\title{
Nutritional Intervention for Reproductive Performance in Dairy Animals
}

\section{Suresh F Nipane ${ }^{1 *}$, Ravindrakumar I Hatzade ${ }^{2}$, Shweta R Lende ${ }^{3}$, Bharat L Mundhe ${ }^{1}$ and Amit D Chikhalikar ${ }^{4}$}

${ }^{1} \mathrm{PhD}$ Scholar, NVC, MAFSU, Nagpur, India

${ }^{2}$ PhD Scholar, PGIVAS, MAFSU, Akola, India

${ }^{3}$ Farm Supervisor, NVC, MAFSU, Nagpur, India

${ }^{4} \mathrm{PhD}$ Scholar, BVC, MAFSU, Mumbai, India

*Corresponding Author: Suresh F Nipane, PhD Scholar, Department of Animal

Nutrition, NVC, MAFSU, Nagpur, India.
Received: October 13, 2021

Published: November 09, 2021

(C) All rights are reserved by Suresh F

Nipane., et al.

\begin{abstract}
Nutrient deficiencies cause a variety of problems in animals, including reduced reproductive performance. Macronutrients are the most important nutrients for dairy cattle reproduction, and they should be given top priority. Micronutrients are required for proper cellular metabolism, growth, and maintenance, as well as animal fertility and health. For a variety of metabolic activities, including reproduction and growth, adequate nutritional supplementation and absorption are essential.
\end{abstract}

Keywords: Nutrients; Reproduction; Macronutrients; Micronutrients; Fertility

\section{Abbreviations}

DMI: Dry Matter Intake; NEB: Negative Energy Balance; IGF: Insulin-Like Growth Factor; NEFA: Non-Esterified Fatty Acid; BCS: Body Condition Score; MJ: Mega Joule; ME: Metabolizable Energy; PHGPx: Phospholipid Hydroperoxide Glutathione Peroxidase; FSH: Follicle Stimulating Hormone; LH: Luteinising Hormone; PBI: Protein Bound Iodine; DNA: Deoxyribonucleic Acid; DM: Dry Matter; BW: Body Weight

\section{Introduction}

Nutrition and reproduction are two of the most important aspects of profitable dairy production, and nutrition has a key impact on reproductive performance in dairy animals. Due to diet, management, and expression and detection of estrus, genetic improvement in dairy cows has resulted in a major increase in milk supply, which has been linked to a drop in reproductive performance [13]. Increasing dry matter intake (DMI), manipulating carbohydrate fractions, maintaining adequate effective fiber, feeding supplemental fats, avoiding excessive or inappropriate protein, optimiz- ing mineral and vitamin levels, and minimizing the risk of known toxins are all examples of nutritional management efforts to reduce the impact on reproduction. Imbalanced nutrition causes delayed puberty, the post-partum interval to conception to be longer, normal ovarian cyclicity to be disrupted and infertility. Low reproductive performance due to nutritional inadequacies caused by high output and inadequate feeding. Nutritional measures to maintain a healthy immune system may have reproductive benefits and enhances fertility.

Major nutrients for reproductive performance are Water, Carbohydrate, Fat and Fatty Acids, Proteins, Vitamins, and Minerals.

\section{Water}

Water is universal nutrients because in the universe each and every live species require water for their various metabolic activity. As concern to reproduction, water is a fluid part and is present in the form of amniotic and allantoic fluid in the amniotic and allantoic cavity respectively. In early pregnancy, amniotic and allantoic 
fluid and goes on increase as pregnancy goes advances. Nutrients are gain from the mother through the placenta that diffuse in amniotic and allantoic fluid and get nutrients to the developing fetus and sometimes the fetus just swallows the fetal fluid for obtaining the nutrients [4]. The requirement of water to dairy animals is about 3-5 lit/DMI or 38-120 lit/day/head.

\section{Carbohydrate}

Carbohydrate is the primary source of energy for animals obtained through feed, and because the carbohydrate component is larger than other nutrients, it gives energy to animals. Positive and negative energy balance exists in the body.

\section{Positive energy balance}

Excessive energy consumption during late lactation and dry seasons can result in "fat cow" issues. When cows calve, they are more likely to have a retained placenta, uterine infections, cystic ovaries, low fertility, and protracted calving periods.

\section{Negative energy balance and body condition score}

Animals' feed intake drops a few weeks before parturition due to stress, and it stays low until the fourth week after parturition, but their energy requirements rise to maintain body condition and milk production after parturition. When animals are unable to obtain sufficient energy from rations, they begin to mobilize body fat reserves to meet their energy demands [5] and enter a state of NEB. NEB cows exhibit lower plasma glucose, insulin, insulin-like growth factor I (IGF I), lower plasma progesterone, and diminished ovarian function [6]. Losses in body condition during the early postpartum period amplify the incidences of postpartum anovulation and anestrous, as well as diminished fertility [7].

Dairy cows are exposed to a high concentration of non-esterified fatty acids, or NEFA, during the NEB period. These fatty acids are delivered to numerous organs, most notably the liver, where they are oxidized for energy or converted to ketone bodies before being re-esterified to triacylglycerols. If the liver is unable to expel triacylglycerols - a very low-density lipoprotein - into the blood, triacylglycerols can build up in the liver, resulting in fatty liver. Periparturient cows are more prone to metabolic problems, infections, and infertility as a result of the NEB and its repercussions. Postpartum ovarian function is harmed by high NEFA blood levels. Ketosis retained the placenta, and changes in blood metabolite and hormone profiles have all been associated with NEFA [8]. Body
Condition Score (BCS) can be used to assess the nutritional quality of dairy animals, and BCS is closely connected to reproductive efficiency [9]. The BCS of dairy cattle is totally affected by balanced nutrition and nutritional availability [10], however genuine anestrus and aberrant ovarian cyclicity in buffaloes are inversely connected with the BCS [11]. Postpartum anestrus is caused by poor BCS during the early stages of lactation.

Energy requirements to support follicle growth, ovulation, and early pregnancy are extremely low as $3 \mathrm{MJ}$ of ME per day and requirements for maintenance and production are about 60-250 MJ ME per day in a lactating dairy cow.

\section{Fat and fatty acids}

The substrates for reproductive hormone production are fatty acids and cholesterol. Increasing the amount of fat in your diet may raise your reproductive hormone levels (progesterone, prostaglandins). Because the secretion of hormones is dependent on an animal's energy state, ruminant reproduction is tightly linked to its availability of energy [12]. Fatty acids are a vital source of energy, which is why a sufficient amount of fatty acids (2-3 percent) could help dairy animals reproduce better. Supplemental fat has been linked to increased dominant follicle diameter, enhanced oocyte and embryo quality, and improved fertility in dairy cows [13]. Progesterone concentrations and prostaglandin production were higher in supplemented animals [14]. Rumen function is harmed when dietary fat levels are exceeded. Polyunsaturated fatty acids may help improve fertility through a variety of mechanisms.

Fatty acids, which are found in both sperm and seminal plasma, are engaged in a variety of activities that lead to fertilization, including sperm energy metabolism [15]. Bulls' sperm fatty acid profile and sperm quality have been demonstrated to be affected by PUFA supplementation [16]. Because sperm's plasma membrane is rich in polyunsaturated fatty acids (PUFA), particularly the longchain PUFA docosahexaenoic acid and docosapentaenoic acid, lipid peroxidation is quite sensitive to it [17].

\section{Protein}

In the majority of rations, protein is the second most important nutrient. Because a high or low level of protein in the diet lowers reproductive function in dairy animals, the effect of dietary protein on reproduction is a complex process. A high urea level can harm reproduction in a variety of ways. Cows fed excessive pro- 
tein (more than 10-15\% above needs) required more services each conception and calved more frequently [18]. Excessive RDP feeding during the post-parturient phase may aggravate the negative energy balance and prolong the cyclicity resumption. While some nutritionists prefer to feed a lot of protein during the post-partum period to provide more amino acid precursors for gluconeogenesis and tissue repair, others prefer to feed a lot of protein during the post-partum period. The maturation of oocytes and subsequent fertilization or maturation of developing embryos may be hampered if they are exposed to a high level of urea. In dry cows or heifers, however, providing enough energy for the excretion of excess urea may avoid fertility loss. Certain amino acids, such as methionine, cysteine, and histidine, appear to play important roles in improving the structural integrity of the hoof wall and may reduce the risk of lameness, thereby improving estrus expression, energy balance, and, presumably, overall reproductive efficiency.

Increased blood urea nitrogen concentrations are usually linked to infertility [19] which affect oviductal, uterine, and vaginal fluids; altered amounts of magnesium, potassium, phosphorus, or zinc in uterine secretions; or maybe changes in uterine $\mathrm{pH}$ and cause the loss in fertility [20]. High blood urea levels can be harmful to sperm, ovarian follicle development, and embryo development also hormone imbalance. When the blood contains a lot of urea, progesterone levels are low. High protein levels in the early lactating cow may exacerbate the negative energy balance and delay the return of normal ovarian function.

If the whole cottonseed is included gossypol at $15 \%$ of the diet dry matter, seminiferous tubule damage and mid-piece abnormalities in sperm have been observed in bulls following the consumption of $8 \mathrm{~g} /$ day of free gossypol [21-23], resulting in poor sperm motility, morphology, and depressed fertility. Feeding protein and urea, such that early lactating cows have a diet containing $16 \%$ protein and late lactating cows have a diet containing $12 \%$ protein, should optimize the fertility of the cows.

\section{Vitamins}

\section{Vitamin A}

Vitamin A is needed to keep reproductive tract tissue healthy. Its metabolites have an impact on ovarian follicular development, uterine microenvironment, and oocyte maturation [24]. Delay in sexual maturity, miscarriage, the birth of dead or weak calves, retained placenta, and metritis have all been documented in deficient cattle. Diets lacking in $\beta$-carotene cause uterine involution to be delayed, initial estrus after calving to be delayed, ovulation to be delayed, and cystic ovaries to be more common.

In the male, vitamin A insufficiency is linked to the degradation of the testicular germinal epithelium, which leads to spermatogenesis decrease or stoppage [25]. Bulls fed low-vitamin A diets had delayed puberty, decreased libido, and slowed spermatogenesis [26]. Supplementation before and after calving has been shown to improve conception rates. For dairy cows, daily supplementation of 30,000-50,000 units is advised.

\section{Vitamin D}

Normal calcium and phosphorus metabolism necessitate vitamin D. Defects, on the other hand, are uncommon in commercial herds. When cows are exposed, they may not display signs of heat. Anoestrus, metritis, and retained placenta in dairy cows, and impotentia coeundi (normal or slightly diminished libido but unable to copulate due to a malfunction in the locomotory system) in bulls, are all symptoms of vitamin D deficiency. Supplemental vitamin $\mathrm{D}$ is present in most commercial concentrates in proportions adequate to meet the cow's daily requirement of 10,000 IU [27].

\section{Vitamin E}

Vitamin E is an antioxidant that works within cells. Several processes related to the synthesis of steroids, prostaglandins, sperm motility, and embryo development are disrupted in vitamin $\mathrm{E}$ and selenium insufficiency. Negative effects of vitamin E and selenium deficiency in reproductive events, such as ovulation rate, uterine motility, sperm motility, and transport, conception rate and postpartum activities, fetal membrane expulsion embryo survival, and postnatal growth, are not surprising [28].

\section{Vitamin B- complex}

$\mathrm{B}_{12}$ deficiency causes a decrease in appetite and feed intake, which leads to delayed sexual maturity and atrophy of the ovaries and uterus in cows. The likelihood of a deficit is reduced because cows manufacture this vitamin in their rumen. Cobalt is required for the production of vitamin $B_{12}$. Biotin supplementation is required in the event of biotin insufficiency. A daily dose of $200 \mathrm{mg}$ lowers the number of days it takes to conceive [29]. 


\section{Vitamin C}

In roughly $60 \%$ of cows that had problems maintaining pregnancy, ascorbic acid medication helped. It was assumed that the high quantity in the blood during oestrus stimulated the production of ascorbic acid-rich CL after ovulation [30]. In the treatment of sterility in growing bulls or heavily used bulls with a reduction in their ability to impregnate cows, ascorbic acid therapy was found to be effective. Ascorbic acid appears to play a role in virile sperm production. Vitamin C supplementation of 20-40 g/day or $54 \mathrm{mg} /$ $\mathrm{kg} \mathrm{BW/day.}$

Minerals

Macro minerals

- Calcium: The role of Calcium in reproduction is to aid in parturition, muscular contractibility, uterine muscle tone maintenance, and uterine involution. Low blood calcium levels cause involution to be delayed, as well as an increased risk of retained placenta, dystocia, and uterine prolapse [31]. Increased calcium concentration can also reduce cow conception rates by generating a secondary deficit of $\mathrm{P}, \mathrm{Mg}, \mathrm{Zn}, \mathrm{Cu}$, and other trace elements in the intestine, preventing their absorption $[32,33]$. Ca plays a role in sperm motility and viability, as well as antioxidant status by protecting sperm cells from oxidative damage, depending on the stage of sperm maturation $[34,35]$. On a dry matter basis, the calcium-to-protein ratio for dairy cows should be 0.75 to 0.80 percent [27].

- Phosphorus: Phosphorus is found in ATP, which is the primary energy source for most metabolic processes. Phosphorus shortage is usually linked to reproductive insufficiency, which results in decreased ovarian activity, irregular or anestrous periods, and lower conception rates. On a dry matter basis, the ratio should contain a minimum of $0.45-0.50$ percent phosphorus [27].

Trace minerals

- Copper (Cu): $\mathrm{Cu}$ and $\mathrm{Zn}$ are linked to reproductive hormones in a substantial way (progesterone and estradiol). Even if estrus is normal, reproductive difficulties caused by copper deficiency present themselves in a decreased conception rate. Early embryonic mortality, resorption of the embryo, increased retained placentas, and placenta necrosis are all symptoms of copper deficiency. There have been reports of weak and silent heaters. Copper de- ficiency in males causes decreased libido, poorer quality sperm, and severe destruction to testicular tissue, which can make the bull sterile [36,37]. Copper supplementation is required for quality semen generation in dairy calves at a level of $10 \mathrm{ppm}$ whereas a level of $100 \mathrm{ppm}$ is harmful to dairy cows [38].

- $\quad$ Selenium (Se): Selenium is required for proper spermatogenesis. PHGPx appears to play a role in proper sperm motility as a structural protein. Retained placenta, abortion, stillbirth, abnormal estrous cycle, early embryonic mortality, cystic ovaries, and metritis are all reproductive problems in cattle that can be minimized by selenium supplementation [39]. The testes have a high level of selenium, which is necessary for testicular function. In selenium-deficient animals, low sperm production and poor sperm quality, including reduced motility and flagella abnormalities predominantly in the mid-piece, has been a constant finding. Se supplementation has been shown to help cattle retain sperm motility. For ruminants, the diet should contain $0.1 \mathrm{ppm}$ selenium on a dry matter basis [40].

- Zinc: Zinc has a significant role in the repair and maintenance of uterine lining following parturition and early return of post-partum estrus [41]. In animals, zinc is required for the production of testosterone and gonadotrophin-releasing hormone. It stimulates Leydig cells of the testis to produce testosterone. Zn deficiencies have been associated with abortion, fetal mummification, lower birth weight. Delayed puberty and lower conception rates, failure of implantation is also found [36]. In males, Zn deficiency causes have lower concentrations of FSH and LH chiefly in males [42] and cause atrophy of seminiferous tubule and inefficient testicular development in young ones, leading to reduced testicular size, lack of libido, and can adversely affect spermatogenesis $[43,44]$. For all classes of beef cattle, including bulls, the $\mathrm{Zn}$ requirement in the diet is $40 \mathrm{ppm}$ [45], and the toxic Zn dietary concentration is $500 \mathrm{ppm}$.

- Iodine: Iodine has an effect on reproduction because of its effects on the thyroid gland. Iodine deficiency impairs fertility and raises the rate of abortion [46], retained placenta, and postpartum uterine infections [47]. Thyroid dysfunction lowers the rate of conception and ovarian activity. Puberty delay, fertilization failure, libido decline, 
and semen quality deterioration in bulls (Kumar, 2003). Higher PBI, the number of services required, and the time delay between first breeding and conception were all linked to improved reproductive performance [48]. The dietary requirement of iodine is $0.25 \mathrm{ppm}$ [45]. Its maximum toxicity level is $50 \mathrm{ppm}$.

- Cobalt: Vitamin $\mathrm{B}_{12}$ is essential for the conversion of propionate to glucose as well as the metabolism of folic acid. The production of thymine, which is essential for DNA synthesis, requires cobalt. As a result, cobalt plays a crucial role in cell division and has a significant impact on animal growth and reproduction. Reduced fertility and poor conditioning of the developing fetus, extended uterine involution, irregular estrous cycle, reduced conception rates, and early calf mortality are all symptoms of cobalt deficiency in dairy cows $[38,44]$. Dietary cobalt requirement for lactating cow $0.11 \mathrm{ppm}$ [40], while toxic dietary concentration for all cattle classes, including bulls is $10 \mathrm{mg} / \mathrm{kg}$ of DM.

- Manganese: Manganese is important for reproduction and is essential for cholesterol synthesis [49]. Cholesterol synthesis is required for the synthesis of the steroid hormones estrogen, progesterone, and testosterone. It protects bull sperm from lipid peroxidation and oxidative stress, as well as facilitating capacitation and the acrosome response after ejaculation of semen, which is crucial for sperm fertilization with the oocyte. Infertility, fetal development retardation, cystic ovaries, poor follicular growth, delayed ovulation, increased embryonic mortality, and reduced conception rates are all symptoms of manganese deficiency [36,50,51]. Manganese supplementation in dairy animals' feed promotes early postpartum estrous and a higher conception rate. In males, Mn deficiency causes a lack of libido, decreased spermatozoa motility, and an aberrant or reduced amount of sperms in the ejaculate [44]. Dietary Mn supplementation is $40 \mathrm{mg} /$ $\mathrm{kg}$ DMI, with a hazardous dose in the feed of $1000 \mathrm{mg} / \mathrm{kg}$ DMI for all cattle classes.

- Chromium: Chromium is required for the secretion of pregnancy-specific proteins by the uterine endometrium, which aids in the prevention of early embryonic mortality. Follicular maturation and LH release are both influenced by chromium. It may cause a drop in sperm count and fertility, as well as affect embryonic growth and development [52].

- Iron: Iron is present in cells and tissues in the male reproductive system, within Sertoli and Leydig cells are important reservoirs of ferritin. The molecule acts as a readily available source of Fe for the developing spermatozoa while providing an extra layer of protection to the testicular tissue [53]. Fe plays an important role in the synthesis of nucleic acids and proteins, electron transport, cellular respiration, proliferation, and differentiation [54] which are ultimately lead to spermatogenesis and spermatozoa metabolism [53]. Iron deficient animals may be anaemic, which becomes repeat breeders and requires an increased number of inseminations per conception and occasionally may abort. The dietary requirement of iron is $50 \mathrm{ppm}$ and its dietary toxic concentration is $1000 \mathrm{ppm}$.

- Molybdenum: In males, molybdenum deficiency causes decreased libido, spermatogenesis, and sterility; in females, it causes delayed puberty, reduced conception rate, and anestrus [44]. The deficiency of molybdenum is rare because of widely distributed in feeds. The dietary requirement of molybdenum is $10 \mathrm{ppm}$ and cattle and sheep are least tolerant to molybdenum toxicity.

\section{Conclusion}

Nutrition is directly related to reproduction in the dairy cow. Energetic status modulates the secretion of hormones plays key roles in the growth of ovarian follicles, ovulation, corpus luteum formation, and oocyte competence. FA improves reproductive function and fertility. Excess protein reduced reproductive performance through disturbing reproductive hormones in dairy cows. Vitamins improve pregnancy rates. Mineral provides an important role in the fertility of animals to avoid the chances of reproductive failure and other reproductive disorders. Nutrients are either deficient or in excess or capable of altering reproduction, hence there is a need to provide a feeding program for dairy animals that is balanced for all nutrients and meets all known nutrient requirements.

\section{Bibliography}

1. Pryce J E., et al. "Genotype and feeding system effects and interactions for health and fertility traits in dairy cattle". Livestock Production Science 57 (1999): 193-201.

2. Royal M D., et al. "Trends in the fertility in dairy cows in the United Kingdom". Proceedings of the Annual Meeting of the British Society of Animal Science. Abst.1 (1999). 
3. Washburn S P., et al. "Trends in reproductive performance in south-eastern Holstein and Jersey DHI herds". Journal of Dairy Science 85 (2002): 244-251.

4. Fuchs F. "Volume of amniotic fluid at various stages of pregnancy". Clinical Obstetrics Gynaecology 9 (1966): 449-460.

5. Gaillard C., et al. "Effects of live weight adjusted feeding strategy on plasma indicators of energy balance in Holstein cows managed for extended lactation". Animals 10 (2016): 633-642.

6. Gross J J., et al. "Response of the cholesterol metabolism to a negative energy balance in dairy cows depends on the lactational stage". PLOS One 10 (2015): e0121956.

7. Fenwick M A., et al. "Negative energy balance in dairy cows is associated with specific changes in IGF-binding protein expression in the oviduct". Reproduction 135 (2008): 63-75.

8. Esposito G., et al. "Interactions between negative energy balance, metabolic diseases, uterine health and immune response in transition dairy cows". Animal Reproductive Science 144 (2014): 60-71.

9. Devkota B. "Association of nutritional status to reproductive performance in buffaloes". Journal of Agriculture and Forestry University 2 (2018): 1-7.

10. Maina V A., et al. "Effect of body condition score on ovarian activity of Bos indicus (ZEBU) cows". Asian Journal of Scientific Research 1.4 (2008): 421-428.

11. Devkota B., et al. "Seasonal variation of anestrus conditions in buffaloes (Bubalus bubalis) in Southern Nepal". Asian Journal of Animal and Veterinary Advances 7 (2012): 910-914.

12. Wathes D C., et al. "Influence of negative energy balance on cyclicity and fertility in the high producing dairy cow". Theriogenology 68 (2007): S232-S241.

13. Souza J de, et al. "Effects of prill size of a palmitic acid-enriched fat supplement on the yield of milk and milk components, and nutrient digestibility of dairy cows". Journal of Dairy Science 100 (2017): 379-384.

14. Jahani-Moghadam M., et al. "Effect of linseed feeding on blood metabolites, incidence of cystic follicles, and productive and reproductive performance in fresh Holstein dairy cows". Journal of Dairy Science 98 (2015): 1828-1835.

15. Zaniboni L, et al. "Combined effect of DHA and - tocopherol enrichment on sperm quality and fertility in the turkey". Theriogenology 65 (2006): 1813-1827.
16. Gholami H., et al. "Effect of feeding a docosahexaenoic acid-enriched nutraceutical on the quality of fresh and frozen-thawed semen in Holstein bulls". Theriogenology 74.9 (2010): 15481558.

17. Brinsko S P., et al. "Effect of feeding a DHA-enriched nutraceutical on the quality of fresh, cooled and frozen stallion semen". Theriogenology 63 (2005): 1519-1527.

18. Bindari Y R., et al. "Effects of nutrition on reproduction: A review". Advances in Applied Science Research 4.1 (2013): 421429.

19. Butler W R "Review: Effect of protein nutrition on ovarian and uterine physiology in dairy cattle". Journal of Dairy Science 81 (1998): 2533-2539.

20. Melendez P., et al. "Milk, plasma, and blood urea nitrogen concentrations, dietary protein, and fertility in dairy cattle". Journal of the American Veterinary Medical Association 223 (2003): 628-634.

21. Chenoweth P J., et al. "Effects of dietary gossypol on aspects of semen quality, sperm morphology and sperm production in young Brahman bulls". Theriogenology 42 (1994): 1-13.

22. Risco C A., et al. "The effect of gossypol in cottonseed meal on performance and on haematological and semen traits in postpubertal Brahman bulls". Theriogenology, 40 (1993): 629642.

23. Chenoweth P J., et al. "Characterization of gossypol induced sperm abnormalities in bulls". Theriogenology 53 (2000): 1193-1203.

24. Scramuzzal R J and Matin G B. "The importance of interactions among nutrition, seasonality and socio sexual factors in development of hormone free methods for controlling fertility". Reproduction in Domestic Animal 43 (2008): 129-136.

25. Maynard L A., et al. "Reproduction. Animal Nutrition". 7th ed. McGraw-Hill, New York 16 (1979): 472.

26. Schilling E and Krajnc A. "Intensive feeding of young bulls and its effect on ejaculate and testes. Animal Breeding Abstract, 332317". Zuchtungskunde 37 (1964): 1-16.

27. Schweigert F J and Zucker H. "Concentration of vitamin A, beta-carotene, and vitamin $\mathrm{E}$ in individual bovine follicles of different quality". Journal of Reproduction and Fertility 82 (1988): 575-579. 
28. Talavera E., et al. "Relationships among dietary lipid intake, serum cholesterol and ovarian' function in Holstein heifers". Journal of Animal Science 60 (1985): 1045.

29. Hedges J., et al. "A longitudinal field trial of the effect of biotin on lameness in dairy cattle". Journal of Dairy Science 84 (2001): 1969-1975.

30. Phillips $\mathrm{P}$ H., et al. "Sperm stimulation in the bull through the subcutaneous administration of ascorbic acid". Journal of Dairy Science 23 (1940): 873.

31. Morrow D A. "The role of nutrition in dairy cattle reproduction". In: Current Therapy in Theriogenology. Morrow D. A. (Ed.), WB Saunders Company, Philadelphia (1980): 449.

32. Hurley W L and Doane R M. "Recent Developments in the Roles of Vitamins and Minerals in Reproduction". Journal Dairy Science 72 (1989): 784-804.

33. Saba L., et al. "Evaluation of mineral nutrition of milk cows in the period between pregnancies". Archivum Veterinarium Polonicum 25 (1987): 237-246.

34. Eghbali M., et al. "Calcium, magnesium and total antioxidant capacity (TAC) in seminal plasma of Water Buffalo (Bubalus Bubalis) bulls and their relationships with semen characteristics". Veterinary Research Forum 1.1 (2010): 12-20.

35. Prien S D., et al. "Seminal concentrations of total and ionized calcium from men with normal and decreased motility". Fertility and Sterility 54 (1990): 171-257.

36. Kreplin $\mathrm{C}$ and Yaremcio B. "Effects of nutrition on beef cow reproduction". Agdex (2009): 420/51-1.

37. Nix J. "Trace Minerals Important for Goat Reproduction". Sweetlix Livestock Supplement System (2002).

38. Puls R. "Mineral levels in animal health". Diagnostic Data. 2nd Edition. Sherpa International, Clearbrook, BC, Canada (1994).

39. Randhawa SS and Randhawa CS. "Trace element imbalances as a cause of infertility in farm animals". Recent Advances in Animal Reproduction and Gynaecology. Proceedings of the summer institute, held at PAU, Ludhiana on July 25 to Aug 13 (1994): 103-121.

40. Miller JK., et al. "The Ruminant Animal”. In: Church D.C (Ed.), Prentice Hall, New Jersey (1988): 342-400.

41. Greene LW., et al. "Role of trace minerals in cow-calf cycle examined". Feedstuffs 70 (1998): 34.
42. Boland MP. "Trace minerals in production and reproduction in dairy cattle". Advances in Dairy technology 15 (2003): 319330.

43. Mass J. "Relationship between nutrition and reproduction in beef cattle". Veterinary Clinics of North America: Food Animal Practice 3 (1987): 633-646.

44. Kumar S. "Management of infertility due to mineral deficiency in dairy animals". In: Proceedings of ICAR summer school on "Advance diagnostic techniques and therapeutic approaches to metabolic and deficiency diseases in dairy animals". IVRI, Izatnagar, UP (2003): 128-137.

45. National Research Council. "Nutrient requirements of dairy cattle". Seventh revised ed., National Academic Press, Washington, DC, USA (2001).

46. Hetzel B S. "Present Knowledge in Nutrition". L. brown ed. International Life Science Institute Nutrition Foundation, Washington D C (1990): 308-313.

47. Hemken RW. "Iodine". Journal of Dairy Science 53 (1960): 1138-1143.

48. Dabas Y PS., et al. Indian Veterinary Journal 64 (1987): 1950.

49. Kappel LC and Zidenberg S. "Manganese: Present Knowledge in nutrition". In: Brown ML (Ed.), International Life Sciences Institute Nutrition Foundation, Washington (1999): 308.

50. Corrah L. "Trace mineral requirements of grazing cattle". Animal Feed Science and Technology 59 (1996): 61-70.

51. Patterson H H., et al. "Supplementation to meet metabolizable protein requirements of primiparous beef heifers: II. Pregnancy and Economics". Journal of Animal Science 81 (2003): 503-570.

52. Tuormaa T E. "Chromium Selenium Copper and other trace minerals in health and reproduction". Journal of Orthomolecular Medicine 15 (2000): 145-157.

53. Wise T., et al. "Relationships of testicular iron and ferritin concentrations with testicular weight and sperm production in boars". Journal of Animal Science 81.2 (2003): 503-511.

54. Lieu PT., et al. "The roles of iron in health and disease". Molecular Aspects of Medicine 22 (2001): 1-87.

Volume 3 Issue 12 December 2021 (C) All rights are reserved by Suresh F Nipane., et al. 